\title{
Polimorfismo isozimático e potencial de utilização das isozimas como marcadores genéticos em aceroleira(1)
}

\author{
Ricardo Lopes ${ }^{(2)}$, Claudio Horst Bruckner ${ }^{(3)}$ e Maria Teresa Gomes Lopes ${ }^{(2)}$
}

\begin{abstract}
Resumo - A aceroleira (Malpighia emarginata DC.) é uma cultura em expansão no Brasil, principalmente, por causa do elevado teor de vitamina $\mathrm{C}$ de seus frutos; contudo, ainda são escassas as informações sobre a espécie. Este trabalho teve o objetivo de estudar a atividade e o polimorfismo de alguns sistemas isozimáticos de uma coleção de aceroleiras. Foram estudadas as isozimas $\mathrm{IDH}, \mathrm{MDH}, \mathrm{EST}, \mathrm{ACP}, \mathrm{GOT}$, PGM, PGI e POD. Utilizou-se o sistema de eletroforese horizontal em gel de amido e diferentes tampões de gel e cuba. Identificou-se o número de locos e alelos envolvidos no controle genético das enzimas. IDH demonstrou ser dimérica, e foi constatado um loco e dois alelos. PGM apresentou dois locos diméricos, com dois e quatro alelos. EST e POD demonstraram ser monoméricas, com um e dois locos, respectivamente, todos com dois alelos. $\mathrm{MDH}$ apresentou um loco onde o seu comportamento é monomérico e outro dimérico, ambos com dois alelos. GOT foi polimórfico mas não foi possível inferir sobre seu controle genético. O polimorfismo revelado pelos sistemas IDH, MDH, POD, EST, GOT e PGM demonstra o potencial de utilização das isozimas como marcadores genéticos em estudos de conservação e melhoramento de aceroleira.
\end{abstract}

Termos para indexação: Malpighia emarginata, variação genética, análise enzimática, herança genética.

Isozyme polymorphism and potential of utilization of isozymes as genetics markers in West Indian cherry

\begin{abstract}
The West Indian Cherry (Malpighia emarginata DC.) is a crop in expansion in Brazil mainly due to high fruit vitamin $\mathrm{C}$ content. However, there is still little information about the species. The objective of this study was to determine the activity and the polymorphism of isozymes from a collection of West Indian Cherry plants. IDH, MDH, EST, POD, ACP, GOT, PGM and PGI isozymes were studied. Starch gel horizontal electrophoresis and different gel/electrode buffers were used. Number of loci and alleles involved in genetic control of these isozymes were identified. IDH was dimeric and had one locus with two alleles. PGM was monomeric and had two loci, with two and four alleles. POD and EST were monomeric and had one and two loci, respectively, all with two alleles each. MDH had two polymorphic loci, one which was monomeric and one dimeric, both with two alleles each. GOT was polymorphic but its inheritance and genetic control was not determined. Polymorphisms of IDH, $\mathrm{MDH}, \mathrm{POD}, \mathrm{EST}$, GOT and PGM showed potential as genetic markers in West Indian Cherry in studies of conservation and breeding.
\end{abstract}

Index terms: Malpighia emarginata, genetic variation, enzymatic analysis, genetic inheritance.

(1) Aceito para publicação em 12 de fevereiro de 2001. Extraído da Dissertação de Mestrado apresentada pelo primeiro autor à Universidade Federal de Viçosa (UFV), Viçosa, MG.

(2) Escola Superior de Agricultura Luiz de Queiroz, Dep. de Genética, Av. Pádua Dias, 11, CEP 13418-900 Piracicaba, SP. E-mail: rlopes@carpa.ciagri.usp.br, mtglopes@carpa.ciagri.usp.br

(3) UFV, Dep. de Fitotecnia, CEP 36571-000 Viçosa, MG. E-mail: bruckner@mail.ufv.br

\section{Introdução}

A cultura da aceroleira apresenta-se em franca expansão no Brasil e vem despertando grande interesse por parte dos consumidores, produtores, industriais e exportadores, dado o seu alto teor de vitamina C (Paiva et al., 1999). De acordo com Oliveira et al. (1998), a demanda da acerola tende a aumentar; as agroindústrias acusam falta do produto durante 
determinados períodos do ano, e várias empresas estão desenvolvendo programas de ampliação e instalação de pomares. Gonzaga Neto \& Soares (1994) ressaltam a importância social da cultura da acerola, em virtude da exigência de mão-de-obra intensiva, principalmente nas etapas de colheita e de classificação dos frutos, que são feitas manualmente.

A caracterização de plantas frutíferas lenhosas mediante o uso de marcadores genéticos é uma prática de uso comum para fins de melhoramento genético e identificação varietal (Fachinello et al., 2000).

A técnica de eletroforese de isozimas é relativamente barata, acessível, e fornece ampla informação genética. Por isso, mesmo hoje, com técnicas moleculares mais modernas, as isozimas continuam sendo uma classe muito útil de marcadores em análises genéticas que não requeiram amostragem ampla do genoma (Ferreira \& Grattapaglia, 1996).

Isozimas têm sido utilizadas em espécies frutíferas para identificação e caracterização de variedades, como indicador da diversidade genética, em estudos de mapeamento genético e para obtenção de estimativas de taxas de cruzamento natural Padrões isozimáticos foram utilizados na identificação e caracterização de genótipos de mangueira (Degani \& El-Batsri, 1990), quivi (Messina et al., 1991), caqui (Parfitt et al., 1991), videira (Altube et al., 1992), macieira (Manganaris \& Alston, 1993), aceroleira (Souza, 1996) e figo (Elisário et al., 1998) assim como muitas outras espécies.

Em espécies poliembriônicas, as isozimas podem ser utilizadas para distinguir embriões de origem zigótica, da nucelar. Elisário et al. (1999) utilizaram isozimas para identificação de híbridos originados da propagação sexual obtidos a partir do cruzamento de variedades de tangerina mono e poliembriônicas.

Em várias espécies tem sido relatada a associação de alelos isozimáticos e características de interesse, o que permite a seleção indireta com vistas a tais características, ou, ainda, a seleção no estádio de plântula. Em macieira, foi detectada ligação entre o loco isozimático Pgm-1 e um gene que confere resistência à sarna-da-macieira (Manganaris et al., 1994) e também ligação entre o loco isozimático Got-1 e um loco de uma série de alelos de auto-incompatibilidade (Manganaris \& Alston, 1987).
Isozimas foram utilizadas na identificação de progênies oriundas de autofecundação e fecundação cruzada em espécies frutíferas, como abacateiro (Degani \& Gazit, 1984; Goldring et al., 1987) e mangueira (Dag et al., 1999), sendo portanto, úteis para obtenção de estimativas da taxa de cruzamento natural.

Informações relativas à biologia reprodutiva são de suma importância para que se possa planejar e executar o melhoramento da cultura, assim como para definir a viabilidade das estratégias a serem adotadas. Segundo Couceiro (1985), a autopolinização é regra geral em aceroleira. No entanto, de acordo com Magalhães \& Ohashi (1997), a autopolinização e a polinização cruzada são processos efetuados em diferentes graus, dependendo da variedade. As isozimas apresentam-se como uma interessante alternativa no estudo do sistema de cruzamento e esclarecimento sobre taxa de fecundação cruzada de variedades de aceroleira.

O objetivo deste trabalho foi avaliar o polimorfismo de alguns sistemas isozimáticos em folhas de aceroleira e selecionar sistemas polimórficos que apresentem boa definição e possibilitem a interpretação clara da herança das isozimas, visando sua utilização como marcadores genéticos.

\section{Material e Métodos}

Os sistemas isozimáticos estudados foram: Esterase (EST), Peroxidase (POD), Glutamato Oxalacetato Transaminase (GOT), Fosfatase Ácida (ACP), Isocitrato Desidrogenase (IDH), Malato Desidrogenase (MDH), Fosfoglucomutase (PGM) e Fosfogluco Isomerase (PGI). A qualidade da atividade (intensidade das bandas) e da resolução dos sistemas isozimáticos (bandas e separação entre bandas nítidas e ausência de borrões ou arraste) foram avaliadas a partir de diferentes combinações-tampão gel-cuba (Tabela 1).

As amostras foram obtidas de 50 plantas do pomar de aceroleiras da Universidade Federal de Viçosa, instalado no Município de Visconde do Rio Branco, MG, as quais possuíam aproximadamente três anos de idade em agosto de 1997. O pomar foi formado a partir de mudas adquiridas de viveiristas do Estado de Pernambuco, estas, na maioria, de origem sexuada, e, em pequena proporção, de origem assexuada.

Ramos de 10-15 cm de comprimento foram coletados a partir do ápice da planta, colocados em sacos de plástico individuais devidamente identificados e imediatamente 
acondicionados em recipiente de isopor, onde as amostras foram dispostas sobre camadas de gelo picado para que fosse mantida sua integridade. No laboratório, as folhas utilizadas como amostras foram congeladas com $\mathrm{N}$ líquido e maceradas em almofariz de porcelana, previamente resfriado para evitar a elevação da temperatura e a conseqüente desnaturação das enzimas.

A proporção de tecido, por volume de solução extratora, foi de aproximadamente 1:1,5, ou seja, aproximadamente $1 \mathrm{~g}$ de folha para $1,5 \mathrm{~mL}$ de solução extratora. Foi utilizada a solução extratora sugerida por Alfenas (1998). Após a trituração com o auxílio de pinça cirúrgica, o macerado foi adsorvido por tiras de papel cromatográfico Whatman $3 \mathrm{M}$, nas dimensões de $1,2 \times 0,5 \mathrm{~cm}$. Após a adsorção, foi feita a limpeza das tiras, eliminado os resíduos sólidos do macerado, e o armazenamento a $-20^{\circ} \mathrm{C}$

$\mathrm{Na}$ análise eletroforética empregou-se o sistema de eletroforese horizontal em gel de amido (Alfenas, 1998), utilizando amido nacional (maizena), na concentração de $12 \%$. A solução-tampão do gel variou de acordo com o sistema. A composição dos tampões gel-cuba, testados em cada sistema isozimático, encontram-se na Tabela 1. A corrida eletroforética consistiu de uma pré-corrida durante 30 minutos a $150 \mathrm{~V}$, e, após, a uma voltagem de $300 \mathrm{~V}$, até que a frente de migração atingisse $9 \mathrm{~cm}$
Após as corridas, o gel foi cortado horizontalmente em cinco fatias de $2 \mathrm{~mm}$ de espessura, das quais a primeira e a última foram descartadas, por não proporcionarem boa resolução. As fatias foram retiradas e colocadas distendidas em fôrmas do tipo pirex, onde foram imersas na solução corante específica de cada enzima. Após o período de incubação, foi feita a fixação em solução de glicerina a $10 \%$, por cerca de doze horas, em refrigerador a aproximadamente $4^{\circ} \mathrm{C}$. Após a coloração e fixação, a secagem do gel foi realizada pelo método do bastidor, descrito por Alfenas (1998).

Os géis foram colocados sobre o diafanascópio, e as bandas reveladas foram registradas. As bandas foram identificadas a partir da mobilidade relativa $(\mathrm{Mr})$, e foi atribuído o valor 1 para a banda de maior migração, a partir do ponto de aplicação; a mobilidade relativa das demais foi obtida pela divisão da distância percorrida por cada uma pela distância percorrida pela banda de maior migração.

Posteriormente, foi feita a interpretação dos géis por região de migração, visando identificar o loco ou locos envolvidos no controle das enzimas. Com base no número e posição das bandas por região de migração (loco), procurou-se determinar o número de locos e de alelos por loco que a população apresenta, e inferir sobre o controle genético da enzima na espécie.

Tabela 1. Combinações de tampões gel-cuba utilizados nos sistemas isozimáticos avaliados, a partir de enzimas extraídas de folhas de aceroleira.

\begin{tabular}{|c|c|c|c|c|}
\hline \multicolumn{2}{|c|}{ Tampão } & \multirow[t]{2}{*}{ Enzima $^{(1)}$} & \multirow[t]{2}{*}{ Referência } & \multirow[t]{2}{*}{ Resolução $^{(2)}$} \\
\hline Gel & Cuba & & & \\
\hline \multirow{6}{*}{$\begin{array}{l}\text { Tris }(0,015 \mathrm{M}) \\
\text { Ác. cítrico }(0,004 \mathrm{M}) \\
\text { pH } 7,8\end{array}$} & $\mathrm{NaOH}(0,1 \mathrm{M})$ & $\mathrm{ACP}$ & Soltis et al. (1983) & Ruim \\
\hline & Ác. bórico $(0,3 \mathrm{M})$ & GOT & & Boa \\
\hline & $\mathrm{pH} 8,6$ & EST & & Boa \\
\hline & & PGM & & Boa \\
\hline & & PGI & & Boa \\
\hline & & POD & & Boa \\
\hline \multirow{5}{*}{$\begin{array}{l}\text { Tris }(0,045 \mathrm{M}) \\
\text { Ác. cítrico }(0,007 \mathrm{M}) \\
\text { LiOH }(0,004 \mathrm{M}) \\
\text { Ác. bórico }(0,019 \mathrm{M}) \\
\text { pH } 8,5\end{array}$} & $\mathrm{LiOH}(0,038 \mathrm{M})$ & EST & Soltis et al. (1983) & Ruim \\
\hline & Ác. bórico $(0,188 \mathrm{M})$ & $\mathrm{ACP}$ & & Ruim \\
\hline & $\mathrm{pH} 8,3$ & PGM & & Boa \\
\hline & & PGI & & Boa \\
\hline & & GOT & & Boa \\
\hline \multirow{3}{*}{$\begin{array}{l}\text { Tampão da cuba diluído na } \\
\text { concentração } 15: 1 \\
\text { pH } 7,0\end{array}$} & Tris $(0,135 \mathrm{M})$ & $\mathrm{ACP}$ & Shaw \& Prasad (1970) & Ruim \\
\hline & Ác. bórico $(0,043 \mathrm{M})$ & $\mathrm{MDH}$ & & Boa \\
\hline & $\mathrm{pH} \mathrm{7,0}$ & $\mathrm{IDH}$ & & Boa \\
\hline \multirow{4}{*}{$\begin{array}{l}\text { Ác. cítrico }(0,5 \mathrm{M}) \\
\text { Tris }(0,19 \mathrm{M}) \\
\mathrm{pH} 8,13\end{array}$} & $\mathrm{NaOH}(0,1 \mathrm{M})$ & $\mathrm{ACP}$ & Brown (1978) & Ruim \\
\hline & Ác. bórico $(0,3 \mathrm{M})$ & GOT & & Boa \\
\hline & $\mathrm{pH} 8,7$ & EST & & Boa \\
\hline & & POD & & Boa \\
\hline
\end{tabular}

(1)ACP: fosfatase ácida; GOT: glutamato oxalacetato transaminase; EST: esterase; PGM: fosfoglusomutase; PGI: fosfogluco isomerase; POD: peroxidase; MDH: malato desidrogenase; IDH: isocitrato desidrogenase. (2)Resolução boa: atividade e resolução satisfatória; resolução ruim: atividade ou resolução insatisfatória 


\section{Resultados e Discussão}

Apenas no sistema ACP não foi obtida boa resolução, apesar de terem sido testados três sistemastampões (gel-cuba) (Tabela 1).

Não foi verificada perda de atividade das enzimas presentes nas amostras preparadas e armazenadas a $-20^{\circ} \mathrm{C}$ nos sistemas IDH, MDH, EST, POD, GOT, PGM e PGI, até aproximadamente 150 dias; após esta data, não foram feitas avaliações. A estabilidade da amostra da enzima ACP não foi avaliada, por não ter sido obtida boa resolução com os sistemas tampões testados. O período de conservação da atividade das enzimas demonstra que a solução extratora sugerida por Alfenas (1998) foi eficiente na conservação da integridade das amostras, e, com exceção do sistema $\mathrm{ACP}$, proporcionou boa resolução em pelo menos uma das combinações de tampão testadas, e portanto é adequada para a extração de isozimas de folhas de aceroleira.

A enzima IDH apresentou apenas uma região de migração, revelou-se dimérica, e foram constatados dois alelos e três fenótipos ou padrões de segregação (Figura 1). O número de subunidades apresentado está de acordo com o descrito por outros autores (Oliveira, 1997; Brune et al., 1998; Junghans et al., 1998).

A enzima MDH apresentou três regiões de migração. Na região I, correspondente ao loco Mdh-1, os fenótipos isozimáticos observados demonstram comportamento monomérico. Já na região II, correspondente ao loco Mdh-2, embora também tenham sido constatados dois alelos, os fenótipos isozimáticos observados demonstram ser a enzima dimérica, uma vez que, em estado de heterozigose, foram observadas três bandas, sendo a intermediária correspondente ao heterodímero. Na região III, foram observadas três bandas, invariavelmente, em todas as plantas caracterizadas (Figura 2).

A ocorrência de isozimas monoméricas e diméricas no sistema MDH também foi constatada por Schuelter (1996), em pimenta. Souza (1996) obteve semelhante padrão de segregação da enzima $\mathrm{MDH}$, em aceroleira. $\mathrm{O}$ autor observou três bandas monomórficas na região de menor migração, correspondentes às bandas monomórficas apresentadas na Figura 2B e constatou comportamento dimérico em um loco situado na região de migração intermediária do gel.
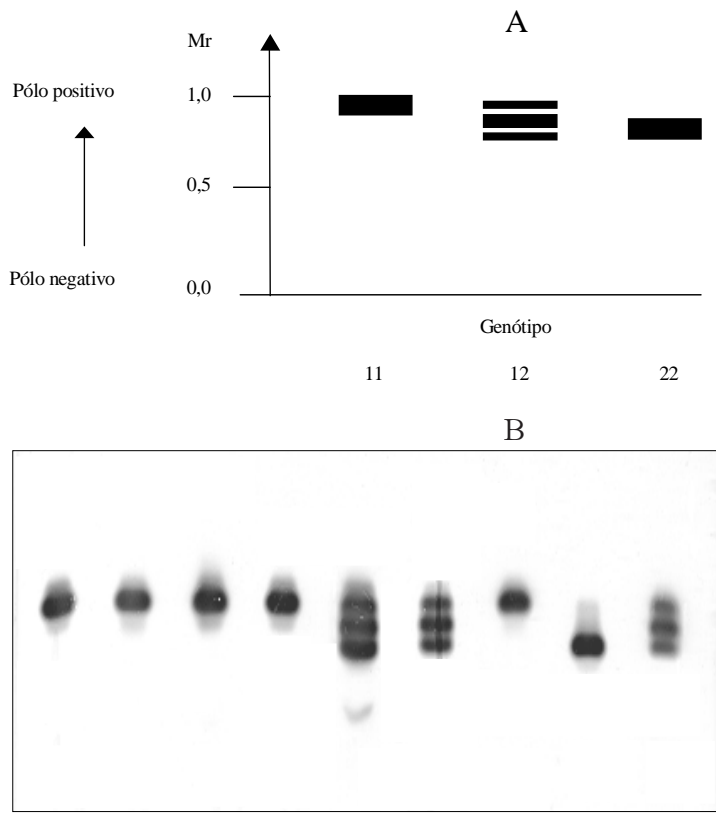

Figura 1. Representação esquemática (A) e imagem de um gel (B) com base na mobilidade relativa das bandas no gel (Mr), dos fenótipos e genótipos isozimáticos da enzima Isocitrato Desidrogenase, observados nas análises eletroforéticas de amostras obtidas de folhas de aceroleira

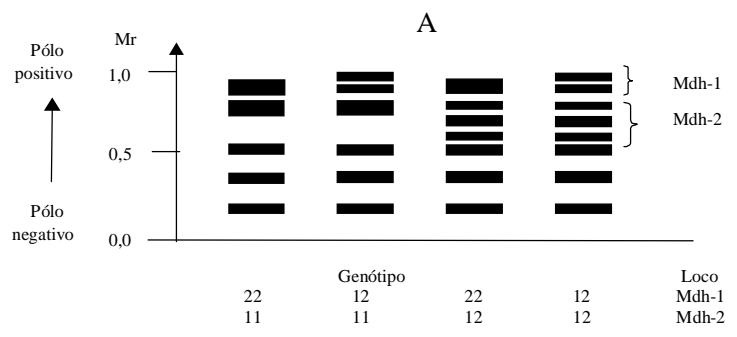

B

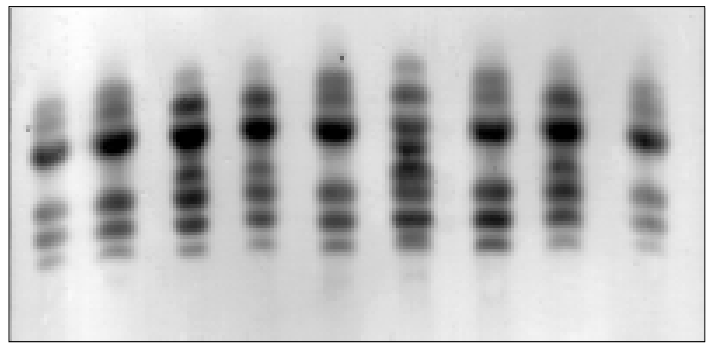

Figura 2. Representação esquemática (A) e imagem de um gel (B) com base na mobilidade relativa das bandas no gel (Mr), dos fenótipos e genótipos isozimáticos da enzima Malato Desidrogenase (MDH), observados nas análises eletroforéticas de amostras obtidas de folhas de aceroleira. 
No entanto, os padrões de bandeamento que ele detectou na região de maior migração não permitiram que fossem feitas inferências sobre o comportamento da enzima.

A enzima EST apresentou comportamento monomérico e foram observados dois locos (Figura 3). Em ambos os locos foram constatados dois alelos, de maneira que fenótipos de duas bandas correspondem à heterozigose, e os de uma, ao estado de homozigose. Tal comportamento também foi verificado em aceroleira por Souza (1996).

A complexidade dos fenótipos isozimáticos apresentados com relação à enzima GOT (Figura 4B) não permitiram identificar o tipo de segregação e o número de alelos envolvidos. Foram verificadas cinco bandas e fenótipos formados por uma, duas, três e quatro bandas. O polimorfismo detectado foi do tipo presença/ausência de bandas, e todas as bandas foram polimórficas. Alguns dos fenótipos isozimáticos são apresentados esquematicamente na Figura 4A.

Os fenótipos isozimáticos revelam que a enzima Peroxidase é monomérica. Foram observados dois alelos e três fenótipos, dois correspondentes ao estado de homozigose, e um, ao de heterozigose. O número de alelos e os fenótipos observados são semelhantes aos obtidos em aceroleira por Souza (1996), mas o autor relata que a banda de maior migração apresentou fraca intensidade, mesmo em homozigose. Verificou-se que, em homozigose, a banda de maior migração apresentou coloração bem mais intensa do que quando em heterozigose (Figura 5). As diferenças entre os resultados se devem à qualidade de resolução do sistema-tampão utilizado. A constituição monomérica da enzima POD e a presença de dois alelos também foram observadas por Oliveira (1997), em picão (Bidens pilosa L.).

Dois locos polimórficos foram detectados a partir da atividade da enzima PGM. No loco Pgm-1, região de maior migração no gel, foram encontrados dois alelos, e no Pgm-2, de menor migração, foram constatados quatro. Os padrões eletroforéticos constam da Figura 6. A enzima demonstrou ser composta por apenas uma subunidade, monomérica, o que é evidenciado pela ausência da banda intermediária nos indivíduos heterozigotos. Tal constatação está de acordo com Brune et al. (1998).

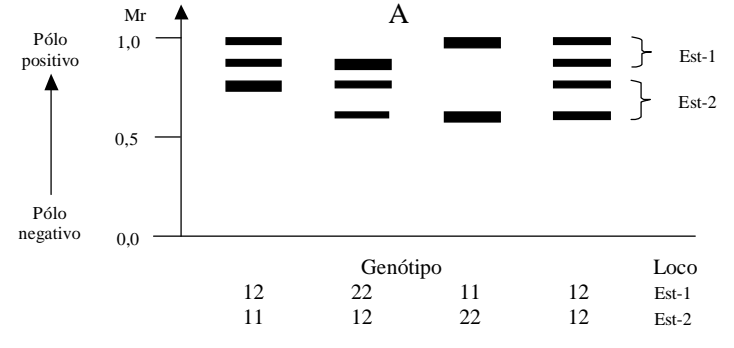

B

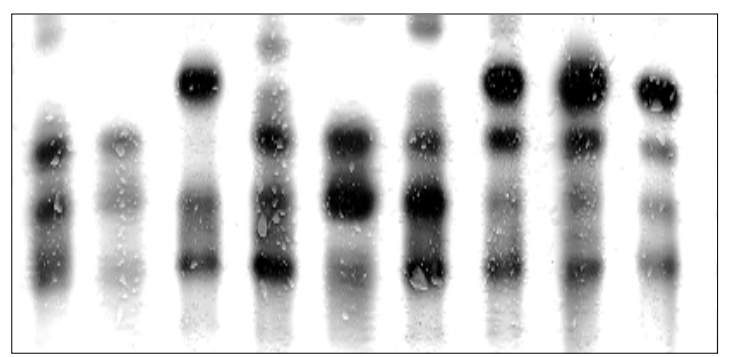

Figura 3. Representação esquemática (A) e imagem de um gel (B) com base na mobilidade relativa das bandas no gel (Mr), de alguns fenótipos e genótipos isozimáticos da enzima Esterase (EST) observados nas análises eletroforéticas de amostras obtidas de folhas de aceroleira.
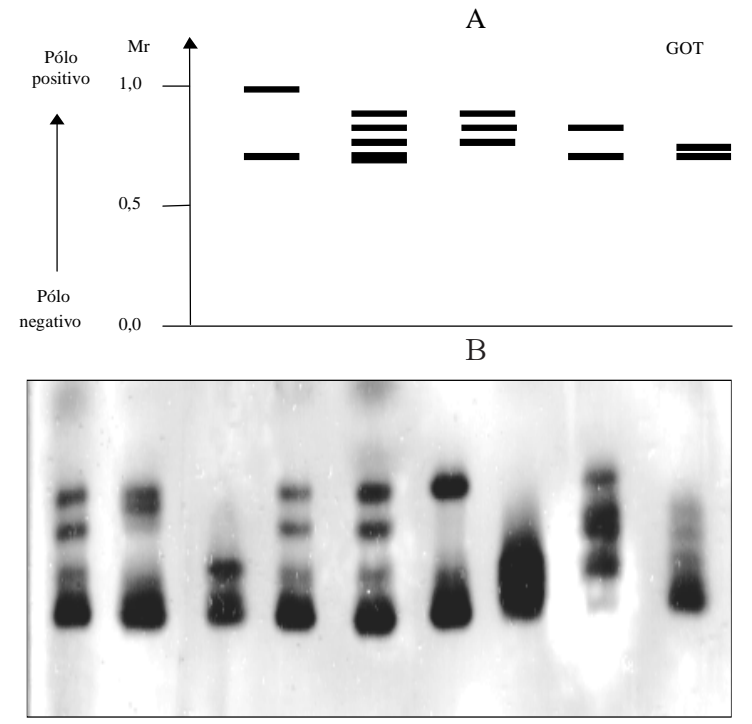

Figura 4. Representação esquemática (A) e imagem de um gel (B) com base na mobilidade relativa das bandas no gel (Mr), de alguns fenótipos isozimáticos da enzima Glutamato Oxalacetato Transaminase (GOT), observados nas análises eletroforéticas de amostras obtidas de folhas de aceroleira.

Pesq. agropec. bras., Brasília, v. 37, n. 2, p. 151-158, fev. 2002 


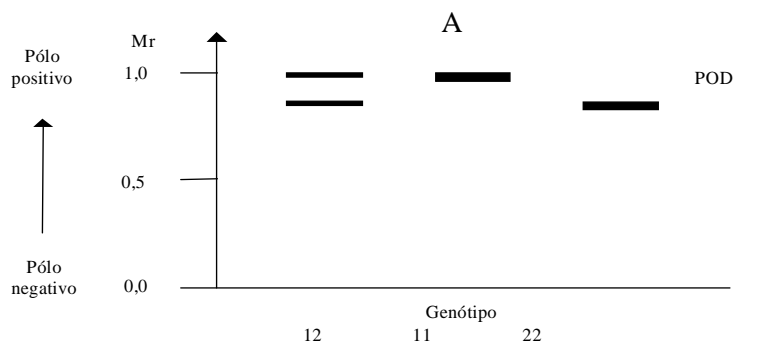

B

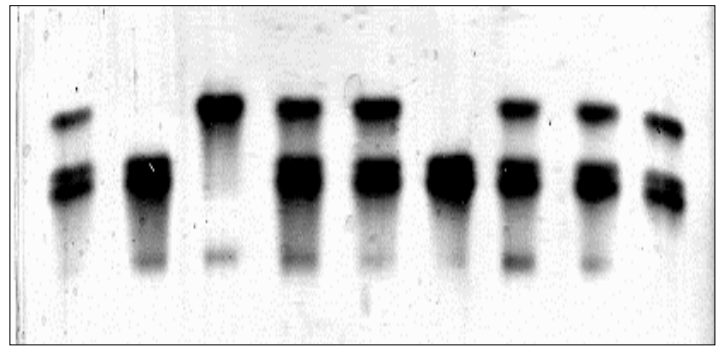

Figura 5. Representação esquemática (A) e imagem de um gel (B) com base na mobilidade relativa das bandas no gel $(\mathrm{Mr})$, dos fenótipos isozimáticos da enzima Peroxidase (POD), observados nas análises eletroforéticas de amostras obtidas de folhas de aceroleira.

A

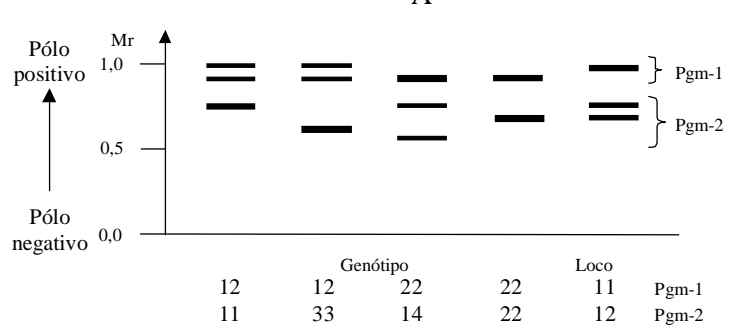

B

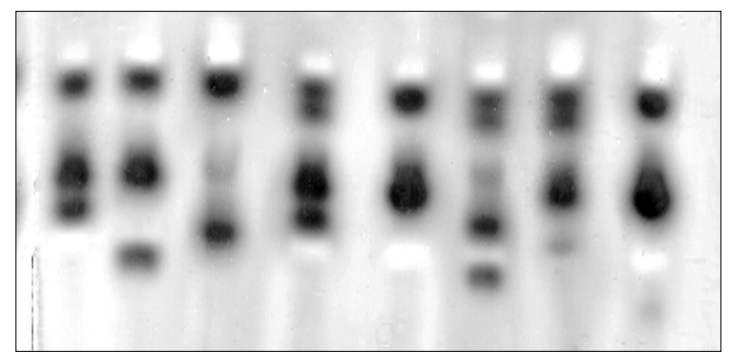

Figura 6. Representação esquemática (A) e imagem de um gel (B) com base na mobilidade relativa das bandas no gel (Mr), de alguns fenótipos e genótipos isozimáticos de Fosfoglucomutase (PGM), observados nas análises eletroforéticas de amostras obtidas de folhas de aceroleira.
A enzima PGI apresentou invariavelmente duas bandas (Figura 7), o que corresponde, provavelmente, a dois locos em homozigose. De acordo com Brune et al. (1998), essa enzima é composta por duas subunidades, de maneira que um loco em heterozigose deve apresentar três bandas.

Nas condições testadas, apresentaram-se polimórficos os sistemas IDH, MDH, POD, EST, GOT e PGM, enquanto PGI foi o único sistema invariante (monomórfico). No sistema ACP, não foi obtida qualidade de resolução suficiente para a interpretação dos fenótipos isozimáticos. Pode-se inferir sobre a herança das enzimas IDH, MDH, EST, PGM e POD; tais inferências estão de acordo com citações encontradas na literatura. Os locos polimórficos com número de alelos e a proporção de heterozigotos observada na amostra de 50 indivíduos são representados na Tabela 2, com exceção do loco Est-2, porque, na maioria dos géis não foi obtida boa resolução da região de migração referente a este loco, deixando, assim, dúvida sobre o genótipo correto dos indivíduos.
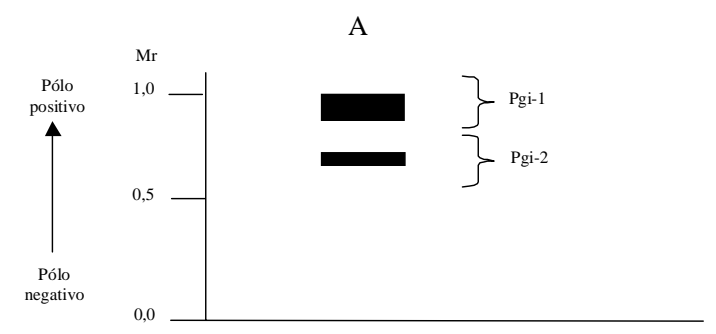

B

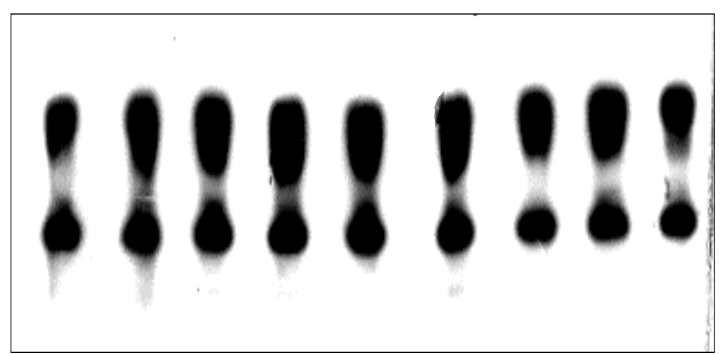

Figura 7. Representação esquemática (A) e a imagem de um gel (B) com base na mobilidade relativa das bandas no gel (Mr), dos fenótipos e genótipos isozimáticos de Fosfogluco isomerase (PGI), observados nas análises eletroforéticas de amostras obtidas de folhas de aceroleira. 
A freqüência de indivíduos heterozigotos variou de 0,18 no loco Mdh-2, a 0,706 no loco Idh-1. Embora não se tenha conhecimento detalhado da origem das plantas que constituem a coleção, e esta não tenha passado por nenhum ciclo de reprodução sexuada, a proporção de indivíduos heterozigotos observados indicou que a espécie apresenta considerável taxa de cruzamento. Esta suposição foi confirmada posteriormente por Lopes (1999). O autor utilizou os sete locos polimórficos apresentados neste trabalho para estimar a taxa de cruzamento natural de dez famílias obtidas a partir de polinização aberta. A taxa de cruzamento das famílias variou de 0,68 a 1,0, demonstrando, assim, que as plantas de aceroleira da coleção são predominantemente alógamas.

Dos sete sistemas testados, seis demonstraram ser polimórficos. Tal fato revela o potencial do uso das isozimas como marcadores genéticos em trabalhos com aceroleira. Mesmo o sistema GOT - para o qual se detectou polimorfismo mas não foram possíveis inferências sobre o comportamento da enzima e número de locos envolvidos - tem potencial como marcador genético em aceroleira. Esses são úteis, por exemplo, em trabalhos de caracterização de germoplasma e diversidade ou divergência genética, tal qual o trabalho de diversidade genética entre acessos de aceroleira realizado por Souza (1996). Nos sistemas que permitiram inferência sobre o tipo de herança, o potencial é mais amplo, podendo, estes sistemas, ser utilizados em estudos de genética de

Tabela 2. Locos polimórficos, número de alelos por loco, e freqüência de heterozigotos observada em uma amostra de 50 indivíduos do pomar de aceroleira da Universidade Federal de Viçosa, MG.

\begin{tabular}{lcc}
\hline Loco & $\begin{array}{c}\text { Número de } \\
\text { alelos/loco }\end{array}$ & $\begin{array}{c}\text { Freqüência de } \\
\text { heterozigotos } \\
\text { observada }\end{array}$ \\
\hline Idh & 2 & 0,706 \\
Mdh-1 & 2 & 0,428 \\
Mdh-2 & 2 & 0,180 \\
Est-1 & 2 & 0,280 \\
Pod & 2 & 0,389 \\
Pgm-1 & 2 & 0,359 \\
Pgm-2 & 4 & 0,444 \\
\hline Média & 2,29 & 0,398 \\
\hline
\end{tabular}

populações, na verificação da validade de cruzamentos e na estimativa da taxa de cruzamento natural.

Outra utilidade das isozimas é a de se poder selecionar precocemente, com elas, características de interesse quando se detecta ligação entre o marcador e o loco de controle da característica. Pressupõe-se, para tanto, que, além da ligação, o marcador não seja afetado pelo estádio de desenvolvimento da planta. Lopes (1999) constatou, por meio da caracterização de plantas com cinco meses de idade, que a atividade enzimática dos sistemas estudados apresentada no referido estádio não difere da atividade detectada em plantas adultas de aceroleira (de aproximadamente três anos)

\section{Conclusões}

1. O polimorfismo revelado pelos sistemas IDH, MDH, POD, EST, GOT e PGM demonstra o potencial de utilização das isozimas como marcadores genéticos em aceroleira.

2. O sistema PGI demonstra-se invariante em aceroleira e não é útil para ser utilizado como marcador genético na espécie.

3. A alta proporção de heterozigotos, observada entre as plantas amostradas, indica ocorrência de alta taxa de cruzamento em aceroleira.

\section{Referências}

ALFENAS, A. C. (Ed.). Eletroforese de isoenzimas e proteínas afins: fundamentos e aplicações em plantas e microorganismos. Viçosa, MG: UFV, 1998. 574 p.

AltuBE, H. A.; CABELlO, F.; ORTiZ, J. M. Caracterización de variedades y portainjertos de vid (Vitis vinifera L.) mediante isoenzimas de las raíces. Agriscientia, Córdoba, v. 9, n. 2, p. 21-29, 1992

BROWN, A. H. D. Isozymes, plant population genetics structure and genetic conservation. Theoretical and Applied Genetics, Berlin, v. 52, p. 145-157, 1978.

BRUNE, W.; ALFENAS, A. C.; JUNGHANS, T. G. Identificações específicas de enzimas em géis. In: ALFENAS, A. C. (Ed.). Eletroforese de isoenzimas e proteínas afins: fundamentos e aplicações em plantas e microorganismos. Viçosa, MG: UFV, 1998. p. 201-328

COUCEIRO, C. M. Curso de extensão sobre a cultura da acerola. Recife: UFRPE, 1985. 45 p. 
DAG, A.; GAZIT, S.; EISENSTEIN, D.; EL-BATSRI, R.; DEGANI, C. Effect of the male parent on pericarp and seed weights in several Floridian mango cultivars. Scientia Horticulturae, Amsterdam, v. 82, n. 3/4, p. 325-329, 1999.

DEGANI, C.; EL-BATSRI, R. Enzyme polymorphism in mango. Journal of the American Society for Horticultural Science, Alexandria, v. 115, p. 844-847, 1990

DEGANI, C.; GAZIT, S. Selfed and crossed proportions of avocado progenies produced by caged pairs of complementary cultivars. HortScience, Alexandria, v. 19, v. 2 , p. $258-260,1984$.

ELISIÁRIO, P. J.; JUSTO, E. M.; LEITÃO, J. M Identification of mandarin hybrids by isozyme and RAPD analysis. Scientia Horticulturae, Amsterdam, v. 81, n. 3, p. 287-299, 1999

ELISÁRIO, P. J.; NETO, M. C.; CABRITA, L.; LEITÃO, $\mathrm{J}$. M. Isozyme and RAPD characterization of a collection of fig tree (Ficus carica L.) traditional varieties. Acta Horticulturae, Leuven, n. 480, p. 149-154, 1998.

FACHINELLO, J. C.; MUSACHI, S.; ZUCHERELLI, S.; SANSAVINI, S. Polimorfísmo enzimático nos tecidos de pereira. Pesquisa Agropecuária Brasileira, Brasília, v. 35, n. 7, p. 1427-1432, jul. 2000.

FERREIRA, M. E.; GRATTAPAGLIA, D. Introdução ao uso de marcadores moleculares em análise genética. 2. ed. Brasília: Embrapa-Cenargen, 1996. 220 p

GOLDRING, A.; GAZIT, S.; DEGANI, C. Isozymes analysis of mature avocado embryos to determine outcrossing rate in a 'Hass' plot. Journal of the American Society for Horticultural Science, Alexandria, v. 112, p. $389-392,1987$

GONZAGA NETO, L.; SOARES, J. M. Acerola para exportação: aspectos técnicos da produção. Brasília: Embrapa-SPI, 1994. 43 p. (Publicações Técnicas Frupex, 10).

JUNGHANS, T. G.; PETERS-ROBINSON, I.; BERTOLUCCI, F. L.; ALFENAS, A. C. The use of selfincompatibility in the production of hybrid eucalyptus seed by 'Aracruz Celulose' in Brazil. Genetics and Molecular Biology, Ribeirão Preto, v. 21, n. 3, p. 375379, 1998.

LOPES, R. Polimorfismo, sistema de acasalamento, polinizações, repetibilidade de características do fruto e avaliação de genótipos de aceroleira (Malpighia emarginata DC.). Viçosa, MG: UFV, 1999. 160 p. Dissertação de Mestrado

MAGALHÃES, M. F.; OHASHI, O. S. Pollination and pollen vectors in acerola, Malpighia punicifolia L. Acta Horticulturae, Leuven, v. 437, p. 419-423, 1997.
MANGANARIS, A. G.; ALSTON, F. H. Inheritance and linkage relationships of glutamate oxalacetate transaminase isoenzymes in apple: 1 . The gene got-1, a marker for the sincompatibility locus. Theoretical and Applied Genetics, Berlin, v. 74, n. 1, p. 154-161, 1987.

MANGANARIS, A. G.; ALSTON, F. H. Peroxidase isoenzyme genes in the identification of apple cultivars and Malus species. Journal of Horticultural Science, Ashford, v. 68, n. 5, p. 775-781, 1993

MANGANARIS, A. G.; ALSTON, F. H.; WEEDEN, N. F.; ALDWINCKLE, H. S.; GUSTAFSON, H. L. BROWN, S. K. Isozyme locus Pgm-1 is tightly linked to a gene (V-f) for scab resistance in apple. Journal of the American Society for Horticultural Science, Alexandria, v. 119, n. 6, p. 1286-1288, 1994

MESSINA, R.; TESTOLIN, R.; MORGANTE, M. Isozymes for cultivar identification in kiwifruit HortScience, Alexandria, v. 26, n. 7, p. 899-902, 1991

OLIVEIRA, J. E. Z. Variabilidade isozimática e do teor de óleo em acessos de Bidens pilosa $\mathrm{L}$. Viçosa, MG: UFV, 1997. 72 p. Dissertação de Mestrado.

OLIVEIRA, J. R. P.; SOARES FILHO, W. S.; CUNHA, R. B. da. A cultura da acerola no Brasil. Cruz das Almas: Embrapa-CNPMF, 1998. 35 p. (Documentos, 85).

PAIVA, J. R.; PAIVA, W. O.; CORDEIRO, E. R.; SABRY NETO, H. Parâmetros genéticos em progênies de acerola (Malpighia spp.) de polinização livre. Pesquisa Agropecuária Brasileira, Brasília, v. 34,n. 4, p. 629-634, abr. 1999

PARFITT, D. E.; YONEMORI, R.; RYUGO, K.; SOGIURA, A. Isozyme identification of Japanese persimmons (Diospyrus raki L.): comparisons of cultivars in California and Japan. Fruit Varieties Journal, University Park, v. 45, v. 107-113, 1991

SCHUELTER, A. R. Análise isozimática, dialélica e diversidade da pimenta silvestre (Capsicum flexuosum Sendt). Viçosa, MG: UFV, 1996. 80 p. Dissertação de Mestrado.

SHAW, C. R.; PRASAD, R. Starch gel electrophoresis of enzymes, compilation of recipes. Biochemical Genetics, New York, v. 4, p. 297-320, 1970.

SOLTIS, D. E.; HAUFLER, C. H.; DARROW, D. C.; GASTONY, G. J. Starch gel electrophoresis of ferns: a compilation of griding buffers, gel and electrode buffers, and staining schedules. American Fern Journal, Vienna, Estados Unidos, v. 73, n. 1, p. 9-27, 1983

SOUZA, J. C. Diversidade genética entre acessos de acerola (Malpighia sp.) com base em dados isozimáticos e agronômicos. Viçosa, MG: UFV, 1996. 67 p. Dissertação de Mestrado 